\title{
Improving the Environmental Compatibility of Marine Sensors by Surface Functionalization with Graphene Oxide
}

\author{
Tianjia Jiang, ${ }^{\dagger, \S}$ Longbin Qi, ${ }^{\dagger, \|, \S}$ and Wei Qin* ${ }^{* \dagger, \ddagger \odot}$ \\ ${ }^{\dagger}$ CAS Key Laboratory of Coastal Environmental Processes and Ecological Remediation and Shandong Key Laboratory of Coastal \\ Environmental Processes, Yantai Institute of Coastal Zone Research (YIC), Chinese Academy of Sciences (CAS), Yantai, Shandong \\ 264003, P. R. China \\ ${ }^{\ddagger}$ Laboratory for Marine Biology and Biotechnology, Qingdao National Laboratory for Marine Science and Technology, Qingdao, \\ Shandong 266237, P. R. China \\ "University of Chinese Academy of Sciences, Beijing 100049, P. R. China
}

Supporting Information

\begin{abstract}
Improving the durability relating to biofouling resistance is still a major challenge for sensors applied in marine monitoring. Herein, a novel antifouling approach implementing biofouling resistance without compromising the sensor's performance is proposed. A polymeric membrane calcium ionselective electrode ( $\mathrm{Ca}^{2+}$-ISE) is chosen as a model sensor. An antifouling coating based on graphene oxide (GO) can be formed on the sensor's surface via the layer-by-layer technique in a simple and controllable manner. The GO coating works as a protection layer to impede the settlement of marine bacterial cells on the sensor surface due to its dual functionality of both antiadhesive and antimicrobial properties. The assembly of the GO coating does not influence the sensor's performance in
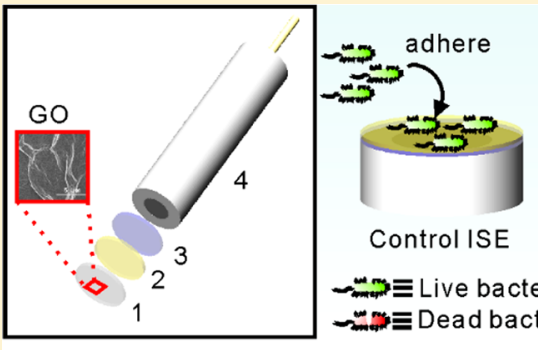

Control ISE

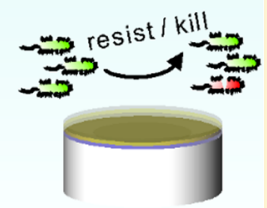

GO-coated ISE

$\sim$ Live bacterial cell $\sim$ DDead bacterial cell

1. Antifouling coating based on GO

2. Ion-selective membrane

3. PEDOT:PSS layer

4. Glassy carbon electrode terms of linear range and response slope. The biofouling resistance of the proposed sensor to marine bacterial cells is evaluated by using the colony-forming unit (CFU) counting method and confocal laser scanning microscopy analysis. An improved antimicrobial activity and a significant decrease in the adsorption of bacterial cells are observed for the GO-coated $\mathrm{Ca}^{2+}$-ISE. Moreover, negligible change is observed in the analysis performance of the GO-coated $\mathrm{Ca}^{2+}$-ISE after 7 day exposure to a rather high concentration marine bacterial suspension of

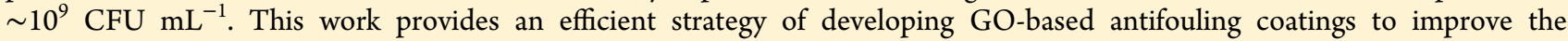
environmental compatibility of marine sensors.
\end{abstract}

$\mathrm{N}$ owadays, many marine environmental monitoring networks using various sensors have been set up around the world to provide a great deal of information about seawater quality, marine ecosystems, and environmental contaminants. ${ }^{1-3}$ However, long-term monitoring with high accuracy and stability is still a challenge for seawater analysis. The difficulty mainly derives from protecting sensors from marine biofouling. $^{4-6}$ The development of marine biofouling on a surface is generally considered to involve four main stages: the adsorption of organic macromolecules to form a conditioning layer within seconds, the adhesion of bacteria and bacterial colonization within minutes or up to hours, the formation of a biofilm occurring over days, and the macrofouling by the large marine invertebrates. ${ }^{4}$ Biofouling can impair the analytical performance of a sensor by instantaneous colonization of organic and biological foulants existing in seawater, which could shorten the sensor's lifetime and cause errors in the collected data. To date, considerable efforts have been devoted to the studies of improving the biocompatibility or blood compatibility of various sensors, ${ }^{7-14}$ but the environmental compatibility of sensors has rarely been studied. In consideration of the negative consequences of marine biofouling, it is of great importance to develop environmentally compatible sensors for reliable marine environmental monitoring.

Antifouling coatings have been highlighted as an effective approach to protect substrates from the direct contact with biological foulants. ${ }^{15}$ The coatings with the dual functionality of both antiadhesive and antimicrobial properties are especially promising, for which hydrophilic polymers such as poly(ethylene glycol) (PEG) and zwitterionic polymers and antimicrobial materials such as Ag nanoparticles and polycations have been developed for antiadhesion and bacterial inactivation, respectively. ${ }^{16-19}$ Despite the excellent fouling resistance exhibited by the combination of the antiadhesive and antimicrobial materials, the fabrication of such coatings

Received: August 29, 2019

Accepted: September 12, 2019

Published: September 16, 2019 


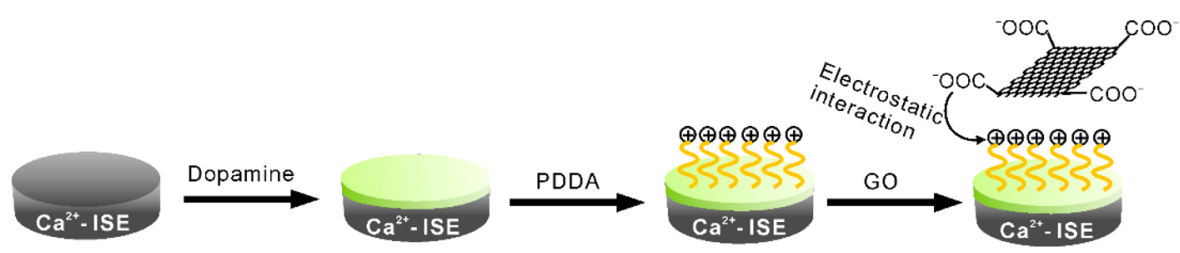

Figure 1. Schematic illustration of the preparation of the GO-coated $\mathrm{Ca}^{2+}$-ISE.

always needs multiple steps to graft the antiadhesive and antimicrobial materials with complex functionalization procedures. Besides, there are still some drawbacks limiting the applications of these materials. For example, PEG-based materials tend to be oxidized in the presence of transition metals and lose the antifouling properties gradually. The immobilization of zwitterionic polymers onto surfaces could be limited by the availability of the reactive functional groups. Silver nanoparticles suffer from the intrinsic tendency to aggregate and pronounced dissolution in aqueous media, leading to a loss of the antimicrobial activity over time. ${ }^{20,21}$

Recently, the antifouling strategies have been enriched by the development of nanomaterials. Graphene oxide (GO), a kind of carbon-based nanomaterial with a high density of oxygen functional groups exposed on its surface, holds great promise to be an antifouling material with both antiadhesive and antimicrobial capabilities. The hydrophilicity of GO can effectively inhibit the adhesion of biofoulants by forming a surface water structure, while the antimicrobial activity of GO is ascribed to the oxidative stress related to its defect density and the edge-mediated physical interactions between the bacterial cells and the sharp edges of GO. ${ }^{22,23}$ In addition, the carboxyl and hydroxyl groups of GO can be deprotonated in a wide $\mathrm{pH}$ range, thus forming a negatively charged surface. Therefore, GO can be readily modified on a substrate via electrostatic and/or hydrogen bonding interactions, rather than complicated chemical grafting processes. Previous research has shown that the incorporation of GO into a membrane could enhance the membrane's resistance to biofouling. $^{24-27}$ However, in that case, the GO material was embedded into the membrane matrix instead of being modified onto the surface. It is known that the antifouling properties of GO result from its contact-mediated mode of action and oxidative stress, ${ }^{28-30}$ and therefore, blending GO into the membrane matrix can lead to a loss of its antifouling activities.

Herein, we propose a novel approach based on surface modification to improve the environmental compatibility of marine sensors. A polymeric membrane ion-selective electrode (ISE) has been selected as a representative sensor to evaluate the impact of the surface modification strategy due to its wide range of applications in environmental analysis. ${ }^{31,32}$ As one of the main ions in seawater, the calcium ion $\left(\mathrm{Ca}^{2+}\right)$ has been selected as the target model. Since the hydrophilic GO material cannot be effectively adsorbed on the hydrophobic membrane surface of the $\mathrm{Ca}^{2+}$-ISE, a hydrophilic polydopamine (PDA) layer is coated on the surface of the $\mathrm{Ca}^{2+}$-ISE through the selfpolymerization of dopamine. A GO coating can then be readily formed on the PDA-modified surface of the membrane electrode via the layer-by-layer ( $\mathrm{LBL}$ ) method based on the electrostatic interactions between polydiallyldimethylammonium (PDDA) and GO. It will be shown that the proposed GO-coated sensor displays a significantly improved environmental compatibility for reducing the adhesion of bacterial cells and inhibiting the formation of biofilms with the attached bacterial cells and bacterial communities enclosed in extracellular polymeric substances and has promising potential for marine environmental monitoring.

\section{EXPERIMENTAL SECTION}

Reagents and Chemicals. $N, N, N^{\prime}, N^{\prime}$-Tetracyclohexyl-3oxapentanediamide (ETH 129), sodium tetrakis [3,5-bis(trifluoromethyl)phenyl] borate (NaTFPB), high molecular weight poly(vinyl chloride) (PVC), 2-nitrophenyl octyl ether $(o-\mathrm{NPOE})$, propidium iodide (PI), and PDDA $(\mathrm{MW}=$ $100000-200000 \mathrm{~g} \mathrm{~mol}^{-1}, 20 \mathrm{wt} \%$ aqueous solution) were obtained from Sigma-Aldrich. The SYTO 9 green-fluorescent nucleic acid stain was received from Invitrogen (Eugene, OR). All the other reagents in this work were of analytical reagent and purchased from Shanghai Chemical Reagent Co., Ltd. (China). Deionized (DI) water (18.2 M $\mathrm{cm}$ specific resistance) was obtained with a Pall Cascada laboratory water system.

Synthesis of GO. GO was synthesized by Hummer's method with minor modifications. ${ }^{33}$ In brief, $0.5 \mathrm{~g}$ of graphite flakes and $0.5 \mathrm{~g}$ of $\mathrm{NaNO}_{3}$ were mixed in a round-bottomed flask containing $23 \mathrm{~mL}$ of $\mathrm{H}_{2} \mathrm{SO}_{4}$ with vigorous stirring for 30 min. After $3.0 \mathrm{~g}$ of $\mathrm{KMnO}_{4}$ was added slowly, the obtained mixture was cooled in an ice bath for $2 \mathrm{~h}$. Then, the reaction temperature was gradually increased to $35{ }^{\circ} \mathrm{C}$ and kept constant for $1 \mathrm{~h}$, and $40 \mathrm{~mL}$ of deionized water was added into the resulting suspension subsequently. Next, the mixture was heated at $90{ }^{\circ} \mathrm{C}$ with stirring for $30 \mathrm{~min}$ and diluted with 100 $\mathrm{mL}$ of DI water and $3 \mathrm{~mL}$ of $30 \% \mathrm{H}_{2} \mathrm{O}_{2}$. Finally, a yellow brown suspension was obtained. The resulting product was separated by filtration and washed with $5 \% \mathrm{HCl}$ solution and DI water three times, respectively. The obtained GO product was dried at $75{ }^{\circ} \mathrm{C}$ for further experiments. GO is negatively charged in a wide range of $\mathrm{pH}$ values since the carboxylic acid $(-\mathrm{COOH})$ groups on its surface can be deprotonated to $\mathrm{COO}^{-} .{ }^{34} \mathrm{~A}$ certain amount of GO was dispersed in DI water to obtain the GO suspension. ${ }^{35}$

Membranes and Electrodes. The calcium ion-selective membrane $\left(\mathrm{Ca}^{2+}\right.$-ISM) cocktail solution was prepared by dissolving $360 \mathrm{mg}$ of membrane components containing $2.3 \mathrm{wt}$ \% ETH 129, 2.2 wt \% NaTFPB, 31.8 wt \% PVC, and 63.7 wt \% $o$-NPOE into $3.6 \mathrm{~mL}$ of THF. The ISM was prepared by pouring $3.6 \mathrm{~mL}$ of the cocktail solution into a glass ring (3.6 $\mathrm{cm}$ in diameter) fixed onto a glass plate. After overnight evaporation, a transparent membrane was obtained.

The solid-contact $\mathrm{Ca}^{2+}$-ISEs were prepared by using poly(3,4-ethylenedioxythiophene):poly(sodium 4-styrenesulfonate) (PEDOT:PSS) as the intermediate layer. Prior to polymerization, a glassy carbon electrode (GCE, $3.0 \mathrm{~mm}$ in diameter) was polished with alumina powder $(0.05 \mu \mathrm{m})$ and sonicated in ethanol and deionized water successively. Then, the PEDOT:PSS film was modified onto the surface of the cleaned GCE by electrochemical polymerization in a solution containing $10 \mathrm{mM}$ 3,4-ethylenedioxythiophene (EDOT) and 
$100 \mathrm{mM}$ PSS using a constant current of $0.01414 \mathrm{~mA}$ for $714 \mathrm{~s}$. The modified electrode was rinsed by DI water and dried overnight at room temperature. $80 \mu \mathrm{L}$ of the $\mathrm{Ca}^{2+}$-ISM cocktail solution was pipetted onto the pretreated GCE and dried for 6 h.

Electrode Surface Modification. The procedures for fabrication of the antifouling $\mathrm{Ca}^{2+}$-ISE are shown in Figure 1. A hydrophilic PDA layer was first coated on the surface of $\mathrm{Ca}^{2+}$ ISE through the self-polymerization of dopamine. The GO material was then modified to the electrode surface by the LBL assembly method based on the electrostatic interactions between PDDA and GO.

For preparation of the hydrophilic PDA layer, the $\mathrm{Ca}^{2+}$-ISE was immersed into a $2 \mathrm{mg} \cdot \mathrm{mL}^{-1}$ dopamine solution in $0.1 \mathrm{M}$ Tris- $\mathrm{HCl}$ buffer at $\mathrm{pH} 8.5$ with stirring for $5 \mathrm{~h}$ in air. After the self-polymerization, the PDA-modified $\mathrm{Ca}^{2+}$-ISE was washed by DI water three times. The resulting $\mathrm{Ca}^{2+}$-ISE was exposed to a 1 wt \% PDDA solution in $0.5 \mathrm{M} \mathrm{NaCl}$ for $10 \mathrm{~min}$ to obtain a positively charged surface, and then, the electrode was immersed in a $0.5 \mathrm{mg} \mathrm{mL}^{-1} \mathrm{GO}$ suspension for $10 \mathrm{~min}$. The GO coating was thus self-assembled on the membrane surface of the $\mathrm{Ca}^{2+}$-ISE. The electrode was rinsed with DI water for 2 min after each immersion step to remove the unabsorbed materials. The antifouling $\mathrm{Ca}^{2+}$-ISEs with the multilayered GO coating were prepared by repeating the above-mentioned LBL process in a successive manner until the coating with a desired layer number was achieved. The same procedures were carried out to modify the GO coating on the surface of $\mathrm{Ca}^{2+}$-ISM for the surface characterization and biofouling experiments. The solid-contact $\mathrm{Ca}^{2+}$-ISE and the $\mathrm{Ca}^{2+}$-ISM without any coating were denoted as the control electrode and control membrane for comparison, respectively.

Surface Coating Characterization. The surface functionalized polymeric membrane $\mathrm{Ca}^{2+}$-ISEs were characterized by an attenuated total reflectance Fourier transform infrared (ATR-FT-IR) spectrometer (Thermo Nicolet iS10 IR). The surface hydrophilicities were evaluated through water contact angle measurements with the sessile drop method recorded by an optical instrument (ADS300, Data Physics, Germany).

EMF Measurements. The electromotive force (EMF) values were measured by an electrochemical workstation (CHI 760D, Shanghai Chenhua Apparatus Corporation, China) at room temperature in the galvanic cell: $\mathrm{Ag} / \mathrm{AgCl} / 3 \mathrm{M} \mathrm{KCl} /$ sample solution/ISM/PEDOT-PSS/GCE. For $\mathrm{Ca}^{2+}$ detection, the membrane electrodes were conditioned in $10^{-3} \mathrm{M}$ $\mathrm{CaCl}_{2}$ solution overnight before use. Selectivity measurements were carried out by using Bakker's method, ${ }^{36}$ and the electrodes were conditioned in $10^{-3} \mathrm{M} \mathrm{NaCl}$ solution overnight before measurements. The ion activity coefficients were calculated by the Debye-Hückel approximation, and the EMF values were corrected with the Henderson equation.

Antimicrobial and Antiadhesive Activities Evaluation. The biofouling resistance of the proposed antifouling $\mathrm{Ca}^{2+}$-ISE to marine bacterial cells was evaluated by using the colony-forming unit (CFU) counting method and confocal laser scanning microscopy (CLSM) analysis after the direct contact with bacterial suspension. The bacterial suspension was prepared by incubating overnight $1 \mathrm{~mL}$ of the fresh seawater samples collected from the Bohai Sea, China with $9 \mathrm{~mL}$ of the sterile Luria-Bertani (LB) medium at $37{ }^{\circ} \mathrm{C}$. Gram-negative bacteria could be predominant in the seawater, such as pseudomonades, luminous bacteria, and vibrios. $1 \mathrm{~mL}$ of the cultured bacterial suspension was then added to $9 \mathrm{~mL}$ of the sterile LB medium and grown at $37{ }^{\circ} \mathrm{C}$ for $2 \mathrm{~h}$. After that, the marine bacterial cells were collected by centrifugation and washed with the sterile $0.9 \% \mathrm{NaCl}$ solution to remove the $\mathrm{LB}$ medium. The cleaned bacterial cells were then suspended in the sterile $0.9 \% \mathrm{NaCl}$ solution to obtain a marine bacterial suspension with a concentration of $10^{8}$ or $10^{9} \mathrm{CFU} \mathrm{mL} \mathrm{m}^{-1}$. The antimicrobial activity of the proposed sensors was evaluated using the CFU enumeration method. The active layer of an antifouling $\mathrm{Ca}^{2+}$-ISM $\left(0.785 \mathrm{~cm}^{2}\right)$ was exposed to the bacterial suspension with a concentration of $10^{8} \mathrm{CFU} \mathrm{mL} \mathrm{mL}^{-1}(0.5 \mathrm{~mL}$. $\mathrm{cm}^{-2}$ ) for $1 \mathrm{~h}$ at room temperature. Then, the antifouling $\mathrm{Ca}^{2+}$ ISM was washed by the sterile $0.9 \% \mathrm{NaCl}$ solution three times and placed in a $10 \mathrm{~mL}$ centrifuge tube containing $5 \mathrm{~mL}$ of the sterile $0.9 \% \mathrm{NaCl}$ solution. The adsorbed bacterial cells were removed from the $\mathrm{Ca}^{2+}$-ISM surface by ultrasonic bath for 5 min. After the cells were diluted 10 times, $100 \mu \mathrm{L}$ of $0.9 \%$ $\mathrm{NaCl}$ solution with the removed bacterial cells was spread on an LB agar plate for overnight incubation at $37^{\circ} \mathrm{C}$. All apparatus used in this study were autoclaved prior to the biological experiments, and the operations were carried out in a biosafety cabinet. The comparison experiments were done in parallel for the control $\mathrm{Ca}^{2+}$-ISM without GO coating.

The antimicrobial and antiadhesive activities of the GOcoated $\mathrm{Ca}^{2+}$-ISEs were further studied visually by confocal laser scanning microscopy analysis after the attached bacterial cells were stained with the live/dead fluorescent dyes. The control and $\mathrm{GO}$-coated $\mathrm{Ca}^{2+}$-ISMs were exposed to a bacterial suspension of $10^{9} \mathrm{CFU} \mathrm{mL} \mathrm{m}^{-1}$ in the same way as for the CFU enumeration experiment. After an exposure of $5 \mathrm{~h}$, the attached bacterial cells on the ISE membranes were stained for $30 \mathrm{~min}$ in the dark at room temperature by $3.34 \mu \mathrm{M}$ SYTO 9 for live cells and $20 \mu \mathrm{M}$ PI for dead cells, respectively. The stained bacterial cells were then observed by confocal laser scanning microscopy (Fluo View FV 1000, Olympus, Japan). The bacterial adhesions on the membranes of the various $\mathrm{Ca}^{2+}$ ISEs were evaluated by calculating the surface coverage of bacterial cells, for which the CLSM images were analyzed via ImageJ Pro software (National Institutes of Health).

\section{RESULTS AND DISCUSSION}

Sensor Design. The antifouling solid-contact polymeric membrane $\mathrm{Ca}^{2+}$-ISE has three layers: the PEDOT:PSS intermediate layer as a solid contact, the ISM layer for sensing $\mathrm{Ca}^{2+}$, and the GO-coated layer for preventing surface biofouling (Figure 2a). The antifouling coating was used to improve the antiadhesive and antimicrobial properties of $\mathrm{Ca}^{2+}$ ISE, thus avoiding the colonization of marine bacterial cells and preventing the formation of biofilm on the sensor's surface (Figure 2b).

Characteristics of the Coated Layers. The ATR-FT-IR analysis was performed to investigate the changes in the surface functional groups on the membranes of $\mathrm{Ca}^{2+}$-ISEs during the LBL assembly process and to further verify the formation of the GO coating. As shown in Figure $3 a$, compared to the control sensor (only with the $\mathrm{Ca}^{2+}-\mathrm{ISM}$ ), the PDA-modified $\mathrm{Ca}^{2+}$-ISE displays a distinct peak at $3170 \mathrm{~cm}^{-1}$ referring to the $\mathrm{N}-\mathrm{H} / \mathrm{O}-\mathrm{H}$ bonds of PDA. The disappearance of this peak is followed by the subsequent modification of PDDA, indicating the coverage of PDDA. For the antifouling $\mathrm{Ca}^{2+}$-ISE with the GO coating, two noticeable peaks can be observed at 1738 and $3360 \mathrm{~cm}^{-1}$, which are ascribed to the carbonyl and hydroxyl groups of GO, respectively, thus indicating the successful 
(a)

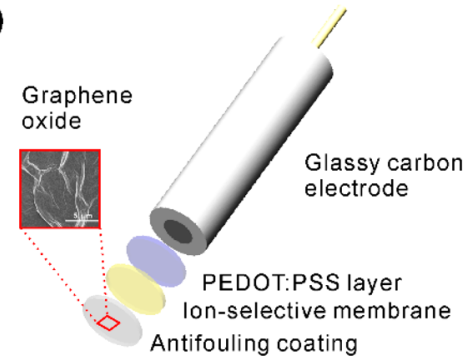

(b)

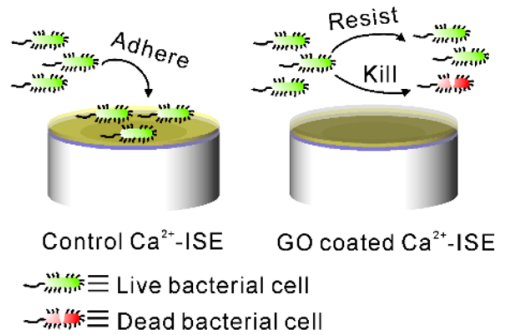

Figure 2. (a) Schematic view of the antifouling solid-contact polymeric membrane $\mathrm{Ca}^{2+}$-ISE. (b) Schematic illustration of the biofouling resistance of the antifouling $\mathrm{Ca}^{2+}$-ISE.
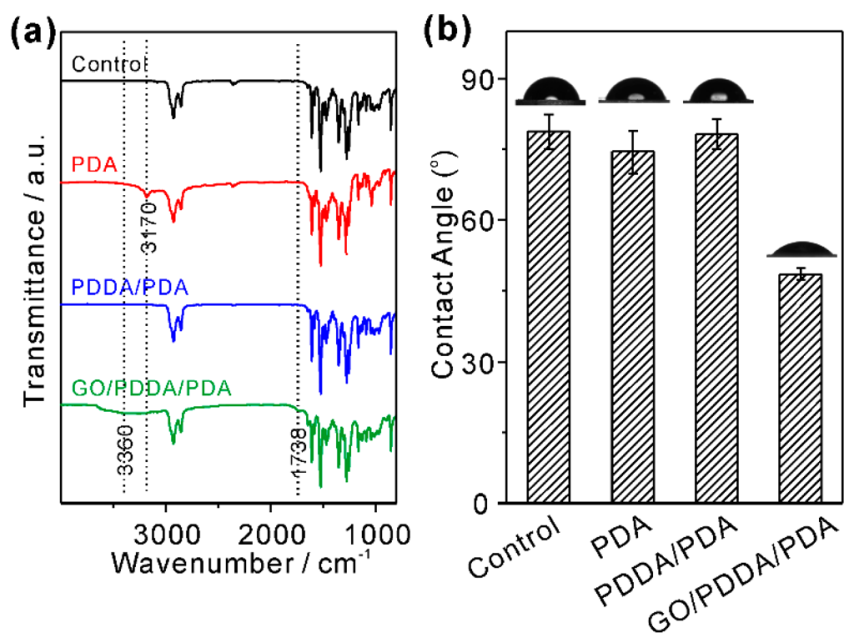

Figure 3. (a) ATR-FT-IR spectra and (b) contact angles for the control, PDA-, PDDA/PDA-, and GO/PDDA/PDA-modified $\mathrm{Ca}^{2+}$ ISEs. Error bars for the contact angle characterization represent one standard deviation for five measurements.

assembly of the GO coating on the membrane electrode surface.

Figure $3 \mathrm{~b}$ shows the contact angles of deionized water on the surfaces of various polymeric membane $\mathrm{Ca}^{2+}$-ISEs. The membrane of the control $\mathrm{Ca}^{2+}$-ISE has an average contact angle of $78.77^{\circ}$. No noticeable changes in contact angle were observed after the modifications of PDA and PDDA, which is likely due to the minimum thicknesses of these materials. However, a remarkable decrease in contact angle can be obtained after the coverage of GO $\left(\sim 48.60^{\circ}\right)$. These results indicate that a much more hydrophilic surface can be formed via GO coating. Experiments also show that the contact angle decreases with an increasing number of the GO/PDDA biolayers up to 3 and thereafter remains almost constant (Figure S1). The hydrophilicity stability of the proposed GOcoated $\mathrm{Ca}^{2+}$-ISEs in seawater was studied. After 14 days of immersion in seawater, negligible changes in contact angle could be observed for the GO-coated polymeric membranes, indicating that the proposed GO-coated $\mathrm{Ca}^{2+}$-ISE could show a stable hydrophilicity in seawater (Figure S2).

Influences of the Surface Coatings on the Sensor's Potential Response. The $\mathrm{Ca}^{2+}$-ISEs coated with different materials were tested in a background similar to seawater (i.e., $0.5 \mathrm{M} \mathrm{NaCl}$ ), and the results are shown in Figure 4. It can be
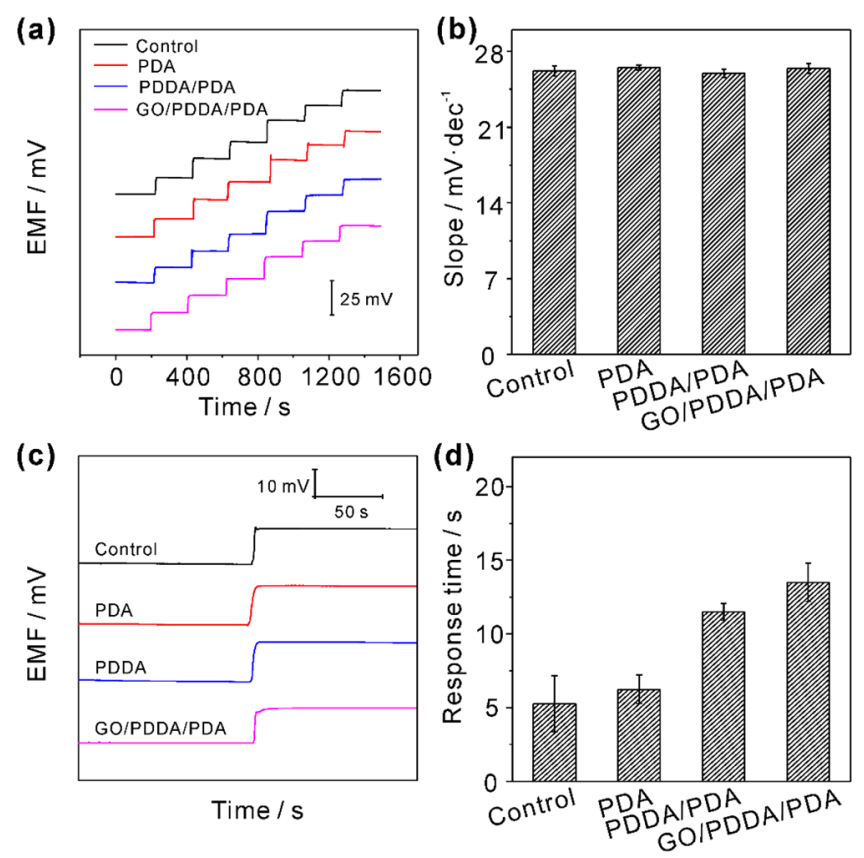

Figure 4. (a,b) Time-dependent potentiometric responses and response slopes of the various $\mathrm{Ca}^{2+}$-ISEs coated with different materials to $\mathrm{Ca}^{2+}$ in the concentration range of $10^{-4}-10^{-1} \mathrm{M}$ with a stepwise increase by $10^{0.5}$ in $0.5 \mathrm{M} \mathrm{NaCl}$. (c) Typical dynamic potential responses with time and (d) the response times of the $\mathrm{Ca}^{2+}$ ISEs coated with different materials when the $\mathrm{Ca}^{2+}$ concentration was increased from $3 \times 10^{-4}$ to $10^{-3} \mathrm{M}$. Error bars represent one standard deviation of three measurements.

seen the assemblies of the PDA, PDDA, and GO layers show little influence on the sensor's performance in terms of linear range and response slope, as compared to the control electrode (Figure 4a,b). However, the response times increase with the successive coverages of PDA, PDDA, and GO layers (Figure $4 c, d)$. It is known that the potentiometric sensor's response is governed by the localized extraction equilibrium. ${ }^{37}$ The surface coatings could affect the ion diffusion process of $\mathrm{Ca}^{2+}$ between the polymeric membrane and the aqueous layer, thus changing the response time; however, since the outer layers cannot impair the final thermodynamic extraction equilibrium state of $\mathrm{Ca}^{2+}$, no change was observed in the sensor's linear range or response slope. ${ }^{37,38}$

It should be noted that the negative effect on response time will be more pronounced when the number of the GO/PDDA biolayers increases. The potentiometric responses of the GOcoated $\mathrm{Ca}^{2+}$-ISEs with various $\mathrm{LBL}$ assembly cycles were measured. Similarly, no obvious change was observed in the potentiometric response in terms of linear range or response slope (Figure S3a,b), but the response time increases with increasing the number of assembly cycles (Figure S3c,d). Considering a short reponse time and high hydrophilicity for the ISE membrane (as discussed above), the antifouling $\mathrm{Ca}^{2+}$ ISE with three bilayers was selected for further experiments. In 
this case, the response time was $18 \mathrm{~s}$ for measuring the $\mathrm{Ca}^{2+}$ concentration change from $3 \times 10^{-4}$ to $10^{-3} \mathrm{M}$, and the contact angle of the modified membrane was $38.47^{\circ}$.

To test the feasibility of the proposed antifouling $\mathrm{Ca}^{2+}$-ISE in a marine environment, the major metal ions (i.e., $\mathrm{K}^{+}, \mathrm{Na}^{+}$, and $\mathrm{Mg}^{2+}$ ) in seawater were selected as the interfering ions to evaluate the selectivity of the antifouling $\mathrm{Ca}^{2+}$-ISE. As shown in Table 1 , all the selectivity coefficients of the antifouling $\mathrm{Ca}^{2+}$.

Table 1. Potentiometric Selectivity Coefficients of the GOCoated and Control $\mathrm{Ca}^{2+}$-ISEs

\begin{tabular}{ccc} 
& \multicolumn{2}{c}{$\log K_{\mathrm{Ca}, \mathrm{j}}^{\mathrm{pot} a}$} \\
\cline { 2 - 3 } ion $\mathrm{j}$ & $\mathrm{GO}$-coated $\mathrm{Ca}^{2+}-\mathrm{ISE}$ & Control $\mathrm{Ca}^{2+}-$ ISE \\
$\mathrm{K}^{+}$ & $-11.46 \pm 0.16$ & $-11.38 \pm 0.18$ \\
$\mathrm{Na}^{+}$ & $-8.64 \pm 0.23$ & $-8.75 \pm 0.10$ \\
$\mathrm{Mg}^{2+}$ & $-9.65 \pm 0.11$ & $-9.53 \pm 0.16$
\end{tabular}

${ }^{a}$ Mean value obtained from three corresponding pairs of concentrations of $\mathrm{Ca}^{2+}$ and the respective interfering cation in the measuring range of $10^{-3}$ to $10^{-1} \mathrm{M} \pm$ standard deviation.

ISE are comparable to these of the control $\mathrm{Ca}^{2+}$-ISE, indicating that the modification of the GO coating does not influence on the selectivity coefficients, which is due to the thermodynamic equilibrium response mechanism of the potentiometric ISE. The excellent selectivity of the antifouling $\mathrm{Ca}^{2+}$-ISE ensures the accurate detection of $\mathrm{Ca}^{2+}$ in seawater (Table S1).

Antimicrobial and Antiadhesive Properties of the GO-Coated $\mathrm{Ca}^{2+}$-ISEs. The antimicrobial capability of the GO-coated $\mathrm{Ca}^{2+}$-ISE was evaluated by the CFU enumeration method. After $1 \mathrm{~h}$ of exposure to a bacterial suspension $\left(10^{8}\right.$ CFU $\mathrm{mL}^{-1}$ ), the adsorbed bacterial cells on the electrode membranes were released and then spread on LB agar plates for counting. As shown in Figure S4, much less live bacterial cells are observed for the membrane of the GO-coated $\mathrm{Ca}^{2+}$ ISE as compared to that of the control $\mathrm{Ca}^{2+}$-ISE, and an inhibition rate of $53.1 \%$ can be obtained. The antimicrobial activity of the GO-coated $\mathrm{Ca}^{2+}$-ISE could be further confirmed by the CLSM analysis via observing the attached bacterial cells on the sensor surface. As shown in Figure 5, the dead and live bacterial cells are observed on the membrane of the control $\mathrm{Ca}^{2+}$-ISE both with large numbers, while the number of dead bacterial cells is much greater than the number of live cells on the membrane of the GO-coated $\mathrm{Ca}^{2+}$-ISE. These results indicate that the proposed sensor displays a good antimicrobial activity. Such an antimicrobial activity may be contributing to the density of defects in the GO structure, which can promote the oxidations of proteins, lipids, and nucleic acids, thus resulting in cell membrane damage and cell death. ${ }^{39,40}$ In addition, the edge-mediated physical interactions between the bacterial cells and the sharp edges of GO could also kill bacterial cells. To investigate the antiadhesive activity of the GO-coated membrane $\mathrm{Ca}^{2+}$-ISE, the obtained CLSM images were analyzed by ImageJ Pro software to calculate the surface coverage of bacterial cells on the control and GO-coated $\mathrm{Ca}^{2+}$ ISEs. As shown in Figure S5, the surface coverage by bacterial cells decreases by $38.6 \%$ after the modification of the GO coating on the polymeric membrane of $\mathrm{Ca}^{2+}$-ISE. Indeed, the increase in the membrane hydrophilicity induced by GO can significantly prevent the sensor's surface from microbial adhesion. ${ }^{41-43}$ The above results confirm that the modification of the GO coating can impart antimicrobial activity as well as antiadhesive properties to the PVC-membrane-based $\mathrm{Ca}^{2+}$-ISE.

Stability of the GO-Coated $\mathrm{Ca}^{2+}$-ISEs in the Presence of Biofoulants. To explore the potentiometric response stability of the proposed $\mathrm{Ca}^{2+}$-ISEs, a series of potentiometric measurements were carried out after contact of the electrodes with a large amount of biofoulants for different periods. Among the primary colonizers, bacterial cells are usually dominant components owing to their high abundances in seawater, ${ }^{44,45}$ so the incubated marine bacterial cells collected from the seawater were selected as biofoulants for this study. Prior to the potentiometric measurements, the control and GO-coated $\mathrm{Ca}^{2+}$-ISEs were immersed into a fresh bacterial suspension of $10^{9} \mathrm{CFU} \mathrm{mL} \mathrm{mL}^{-1}$ in $0.9 \%$ saline solution for the colonization of marine bacterial cells on the polymeric membranes. The changes in electrode slope after the successive exposures to the bacterial suspension for different numbers of days are shown in Figure 6, while the time-dependent potentiometric responses and the corresponding calibration curves of the antifouling and control $\mathrm{Ca}^{2+}$-ISEs are shown in Figures S6 and S7, respectively. It can be seen that the potential response of the GO-coated $\mathrm{Ca}^{2+}$-ISE is rather stable during the test period; in contrast, the response slope of the control $\mathrm{Ca}^{2+}$-ISE decreases gradually with
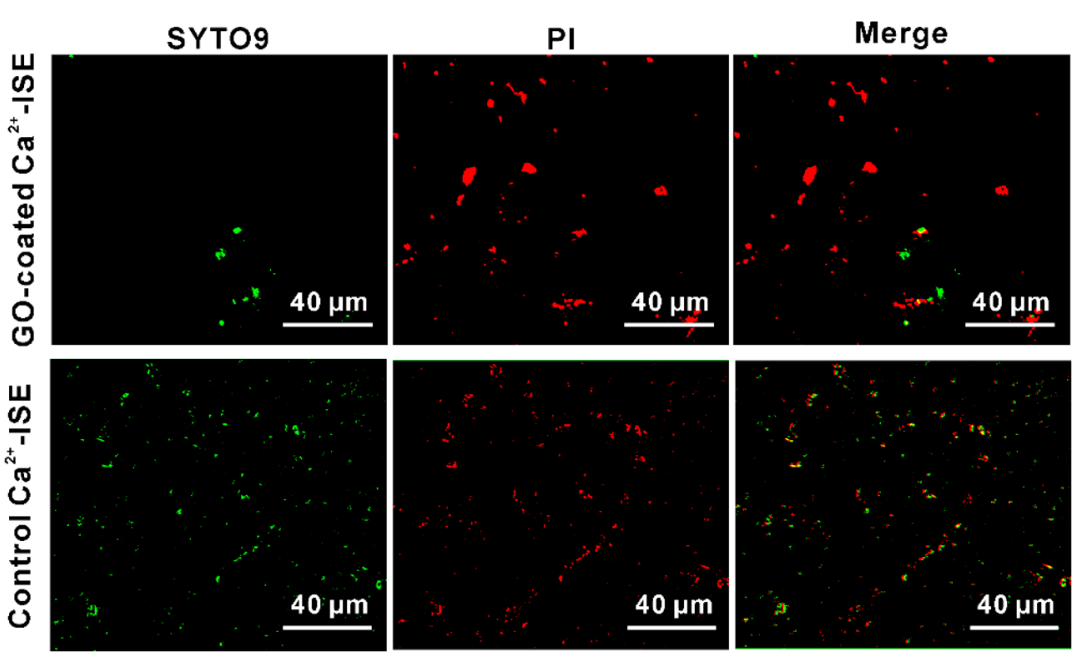

Figure 5. Confocal laser scanning microscopy images of the stained bacterial cells attached on the membranes of the GO-coated and control Ca ${ }^{2+}$. ISEs. The live and dead bacterial cells were stained with SYTO 9 (green) and PI (red), respectively. 


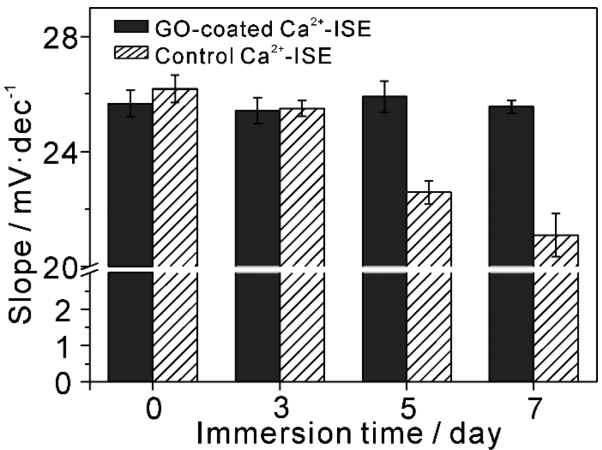

Figure 6. Response slopes of the control and antifouling $\mathrm{Ca}^{2+}$-ISEs after exposure to the marine bacterial suspension $\left(\sim 10^{9} \mathrm{CFU} \mathrm{mL}{ }^{-1}\right)$ for different numbers of days. Error bars represent one standard deviation of three measurements.

increasing the soak time, and a slope loss of $19.4 \%$ is observed after 7 days. For the control electrode, a thick biofilm on the electrode surface could be formed, and the obtained potential response is related to the concentration of $\mathrm{Ca}^{2+}$ in the biofilm instead of the bulk of sample. ${ }^{38}$

It is worth noting that the biofilm that formed onto the polymeric membranes of ISEs can also affect the sensor's response time due to its negative effect on the ion diffusion of $\mathrm{Ca}^{2+}$ between the polymeric membrane and the aqueous layer. As shown in Figure 7a,b, a remarkable increase in response time is observed for the control $\mathrm{Ca}^{2+}$-ISE (i.e., an increase of $16.5 \mathrm{~s}$ for measuring the $\mathrm{Ca}^{2+}$ concentration change from $3 \times$ $10^{-4}$ to $10^{-3} \mathrm{M}$ after contact of the electrode with the bacterial

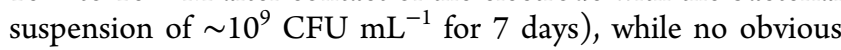
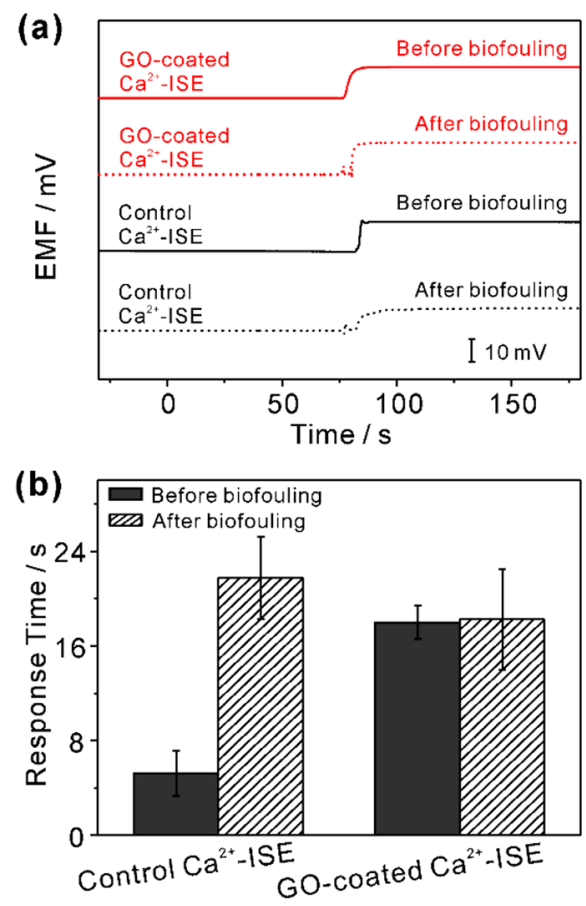

Figure 7. (a) Typical dynamic potential responses with time and (b) the response times of the control and antifouling $\mathrm{Ca}^{2+}$-ISEs when the $\mathrm{Ca}^{2+}$ concentration was increased from $3 \times 10^{-4}$ to $10^{-3} \mathrm{M}$ before and after being immersed in a bacterial suspension $\left(\sim 10^{9} \mathrm{CFU} \mathrm{mL}^{-1}\right)$ for 7 days. Error bars represent one standard deviation of three measurements. change is observed for the GO-coated $\mathrm{Ca}^{2+}$-ISE under the same conditions. These results suggest that the antifouling $\mathrm{Ca}^{2+}$-ISE can maintain an effective biofouling resistance during the exposure period to the bacterial suspension at a rather high concentration.

\section{CONCLUSIONS}

Marine monitoring always suffers from problems of biofouling. Improving the environmental compatibility of marine sensors to avoid the negative effects of biofilms is of great importance. In this work, we propose a simple surface modification strategy based on the GO material to enhance the environmental compatibility of a polymeric membrane calcium ion-selective electrode without compromising the sensor's performance. Compared to the control sensor, the proposed GO-coated sensor displays significantly improved antifouling properties of both antiadhesion and bacterial inactivation, thus reducing the adhesion of bacterial cells and inhibiting the formation of biofilms. We believe that the proposed surface modification strategy based on GO can be applied for developing other antifouling marine sensors to effectively prevent the sensors' passivation resulting from biofouling.

\section{ASSOCIATED CONTENT}

\section{Supporting Information}

The Supporting Information is available free of charge on the ACS Publications website at DOI: 10.1021/acs.analchem.9b03974.

Contact angle of DI water on the membrane of the GOcoated $\mathrm{Ca}^{2+}$-ISE versus the number of $\{\mathrm{GO} / \mathrm{PDDA}\}$ bilayers (Figure S1); hydrophilicity stability of the antifouling coating with three $\{\mathrm{GO} / \mathrm{PDDA}\}$ bilayers in seawater (Figure S2); time-dependent potential responses, response slopes and response times of the antifouling $\mathrm{Ca}^{2+}$-ISEs with $\{\mathrm{GO} / \mathrm{PDDA}\} \mathrm{n}$ multilayers to $\mathrm{Ca}^{2+}$ (Figure S3); colony-forming units of the live bacterial cells attached on the membranes of the control and GO-coated $\mathrm{Ca}^{2+}$-ISEs after contact with a bacterial suspension for $1 \mathrm{~h}$ (Figure S4); surface coverage of the attached bacterial cells on the membranes of the control and $\mathrm{GO}$-coated $\mathrm{Ca}^{2+}$-ISEs after contact with a bacterial suspension for $5 \mathrm{~h}$ (Figure S5); potential responses of the GO-coated and control $\mathrm{Ca}^{2+}$-ISEs after exposure to a bacterial suspension for different numbers of days (Figure S6, S7); determination of the $\mathrm{Ca}^{2+}$ concentrations by the GO-coated $\mathrm{Ca}^{2+}$-ISE and ICP-AES in seawater samples (Table S1) (PDF)

\section{AUTHOR INFORMATION}

\section{Corresponding Author}

*E-mail: wqin@yic.ac.cn; Tel: +86-535-2109156; Fax: +86535-2109000 (W.Q.).

ORCID

Wei Qin: 0000-0002-9606-7730

\section{Author Contributions}

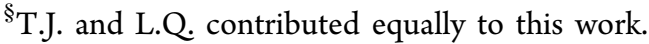

Notes

The authors declare no competing financial interest. 


\section{ACKNOWLEDGMENTS}

This research was financially supported by the National Key Research and Development Program of China (2016YFC1400700), the National Science Foundation of China (41806119, 21677172), the Science Foundation of Shandong Province (ZR2018BB053), and the Taishan Scholar Program of Shandong Province (tspd20181215).

\section{REFERENCES}

(1) Cuartero, M.; Pankratova, N.; Cherubini, T.; Crespo, G. A.; Massa, F.; Confalonieri, F.; Bakker, E. Environ. Sci. Technol. Lett. 2017, $4,410-415$

(2) Wang, Z. A.; Sonnichsen, F. N.; Bradley, A. M.; Hoering, K. A.; Lanagan, T. M.; Chu, S. N.; Hammar, T. R.; Camilli, R. Environ. Sci. Technol. 2015, 49, 4441-4449.

(3) Biard, T.; Stemmann, L.; Picheral, M.; Mayot, N.; Vandromme, P.; Hauss, H.; Gorsky, G.; Guidi, L.; Kiko, R.; Not, F. Nature 2016, 532, 504-507.

(4) Delauney, L.; Compere, C.; Lehaitre, M. Ocean Sci. 2010, 6, 503-511.

(5) Whelan, A.; Regan, F. J. Environ. Monit. 2006, 8, 880-886.

(6) Kroger, S.; Law, R. J. Trends Biotechnol. 2005, 23, 250-256.

(7) Soto, R. J.; Hall, J. R.; Brown, M. D.; Taylor, J. B.; Schoenfisch, M. H. Anal. Chem. 2017, 89, 276-299.

(8) Ghorbanizamani, F.; Timur, S. Anal. Chem. 2018, 90, 640-648.

(9) Berrocal, M. J.; Johnson, R. D.; Badr, I. H. A.; Liu, M. D.; Gao,

D. Y.; Bachas, L. G. Anal. Chem. 2002, 74, 3644-3648.

(10) Jiang, X.; Wang, P.; Liang, R.; Qin, W. Anal. Chem. 2019, 91, 6424-6429.

(11) Frost, M. C.; Rudich, S. M.; Zhang, H. P.; Maraschio, M. A.; Meyerhoff, M. E. Anal. Chem. 2002, 74, 5942-5947.

(12) Schoenfisch, M. H.; Mowery, K. A.; Rader, M. V.; Baliga, N.; Wahr, J. A.; Meyerhoff, M. E. Anal. Chem. 2000, 72, 1119-1126.

(13) Wu, Y. D.; Rojas, A. P.; Griffith, G. W.; Skrzypchak, A. M.; Lafayette, N.; Bartlett, R. H.; Meyerhoff, M. E. Sens. Actuators, B 2007, 121, 36-46.

(14) Espadas-Torre, C.; Oklejas, V.; Mowery, K.; Meyerhoff, M. E. J. Am. Chem. Soc. 1997, 119, 2321-2322.

(15) Banerjee, I.; Pangule, R. C.; Kane, R. S. Adv. Mater. 2011, 23, 690-718.

(16) Liu, S. Q.; Yang, C.; Huang, Y.; Ding, X.; Li, Y.; Fan, W. M.; Hedrick, J. L.; Yang, Y. Y. Adv. Mater. 2012, 24, 6484-6489.

(17) Chen, D. D.; Wu, M. D.; Li, B. C.; Ren, K. F.; Cheng, Z. K.; Ji, J.; Li, Y.; Sun, J. Q. Adv. Mater. 2015, 27, 5882-5888.

(18) Liu, C. H.; Lee, J.; Ma, J.; Elimelech, M. Environ. Sci. Technol. 2017, 51, 2161-2169.

(19) Liu, C. H.; Faria, A. F.; Ma, J.; Elimelech, M. Environ. Sci. Technol. 2017, 51, 182-191.

(20) Daer, S.; Kharraz, J.; Giwa, A.; Hasan, S. W. Desalination 2015, $367,37-48$

(21) Soroush, A.; Ma, W.; Cyr, M.; Rahaman, M. S.; Asadishad, B.; Tufenkji, N. Environ. Sci. Technol. Lett. 2016, 3, 13-18.

(22) Hu, M.; Zheng, S. X.; Mi, B. X. Environ. Sci. Technol. 2016, 50, 685-693.

(23) Mejias Carpio, I. E.; Santos, C. M.; Wei, X.; Rodrigues, D. F. Nanoscale 2012, 4, 4746-4756.

(24) Wang, Z. H.; Yu, H. R.; Xia, J. F.; Zhang, F. F.; Li, F.; Xia, Y. Z.;

Li, Y. H. Desalination 2012, 299, 50-54.

(25) Yu, L.; Zhang, Y. T.; Zhang, B.; Liu, J. D.; Zhang, H. Q.; Song,

C. H. J. Membr. Sci. 2013, 447, 452-462.

(26) Zhang, J. G.; Xu, Z. W.; Shan, M. J.; Zhou, B. M.; Li, Y. L.; Li, B. D.; Niu, J. R.; Qian, X. M. J. Membr. Sci. 2013, 448, 81-92.

(27) Zhang, L. N.; Chen, B. L.; Ghaffar, A.; Zhu, X. Y. Environ. Sci. Technol. 2018, 52, 5920-5930.

(28) Lee, J.; Chae, H. R.; Won, Y. J.; Lee, K.; Lee, C. H.; Lee, H. H.; Kim, I. C.; Lee, J. M. J. Membr. Sci. 2013, 448, 223-230.

(29) Perreault, F.; Jaramillo, H.; Xie, M.; Ude, M.; Nghiem, L. D.; Elimelech, M. Environ. Sci. Technol. 2016, 50, 5840-5848.
(30) Perreault, F.; De-Faria, A. F.; Nejati, S.; Elimelech, M. ACS Nano 2015, 9, 7226-7236.

(31) De-Marco, R.; Clarke, G.; Pejcic, B. Electroanalysis 2007, 19, 1987-2001.

(32) Crespo, G. A. Electrochim. Acta 2017, 245, 1023-1034.

(33) Hummers, W. S.; Offeman, R. E. J. Am. Chem. Soc. 1958, 80, 1339-1339.

(34) Lee, D. W.; Hong, T. K.; Kang, D.; Lee, J.; Heo, M.; Kim, J. Y.; Kim, B. S.; Shin, H. S. J. Mater. Chem. 2011, 21, 3438-3442.

(35) Chung, K.; Rani, A.; Lee, J. E.; Kim, J. E.; Kim, Y.; Yang, H.; Kim, S. O.; Kim, D.; Kim, D. H. ACS Appl. Mater. Interfaces 2015, 7, 144-151.

(36) Bakker, E. J. Electrochem. Soc. 1996, 143, L83-L85.

(37) Xu, Y.; Xu, C.; Shvarev, A.; Becker, T.; De-Marco, R.; Bakker, E. Anal. Chem. 2007, 79, 7154-7160.

(38) Boswell, P. G.; Buhlmann, P. J. Am. Chem. Soc. 2005, 127, $8958-8959$.

(39) Liu, X. Y.; Sen, S.; Liu, J. Y.; Kulaots, I.; Geohegan, D.; Kane, A.; Puretzky, A. A.; Rouleau, C. M.; More, K. L.; Palmore, G. T. R.; Hurt, R. H. Small 2011, 7, 2775-2785.

(40) Gurunathan, S.; Woong Han, J.; Abdal Daye, A.; Eppakayala, V.; Kim, J.-h. Int. J. Nanomed. 2012, 7, 5901-5914.

(41) Rana, D.; Matsuura, T. Chem. Rev. 2010, 110, 2448-2471.

(42) Kochkodan, V.; Hilal, N. Desalination 2015, 356, 187-207.

(43) Morra, M. J. Biomater. Sci., Polym. Ed. 2000, 11, 547-569.

(44) Qian, P. Y.; Lau, S. C. K.; Dahms, H. U.; Dobretsov, S.; Harder, T. Mar. Biotechnol. 2007, 9, 399-410.

(45) Dang, H. Y.; Lovell, C. R. Appl. Environ. Microbiol. 2000, 66, $467-475$. 